\title{
Health Economics I: Basic Economic Principles
}

Using real-world examples, this Continuing Education article examines fundamental economic principles that govern how a price system allocates resources in various industries, especially health care. The article describes the concepts of utility, demand, supply, equilibrium price, the causes of shortages and surpluses, the price system, price discrimination, and the effect of elasticity of demand on a firm's pricing decisions and total revenue. Knowledge of basic economic principles will help pharmacists working in a managed care environment understand and respond to the economic forces shaping the health care market today.

This is the first of two Continuing Education articles that will discuss basic economic principles as they relate to health care in general and pharmacy in particular. This first article is an overview of some of the basic principles of economics with a focus on the price system as a means of allocating resources. The second article will discuss how the economic forces in the health care marketplace compare to those of other industries.

KEYWORDS: Economies, Price system, Resource Allocation, Utility, Demand, Supply, Equilibrium price, Shortage, Surplus, Price discrimination, and Elasticity of Demand

J Managed Care Pharm 2000: 43-50

\section{by Kenneth W. Schafermeyer, Ph.D.}

$\square$ conomics is involved in nearly all contemporary issues facing health care, such as the growing demand for health care services, prices for pharmaceuticals, competition among health care organizations, and remuneration for health care professionals. A lack of understanding of basic economic principles contributes to faulty decision making: people form opinions on issues based on emotions and feel-. ings rather than on sound economic principles.

\section{Economic Concepts in Individual Consumer Decision-Making}

In today's world, consumers' wants may be considered limitless. Our society has never had enough resources to meet the demands of everyone. Because of this scarcity of resources, the science of economics has been developed to help us allocate these resources in the most efficient manner

Economics has been defined as "the study of how individuals and societies allocate their limited resources in attempts 10 satisfy their unlimited wants." The study of economics seeks to answer three important questions:

- What shall we produce with society's limited resources?

- How shall the resources be employed in production? and

- Who shall receive the resulting goods and services?

"Utility" is the economic term for satisfaction obtained from purchasing a particular good or service. Utility is difficult to measure. For example, when a person eats a pizza, he has received some satisfaction, but the amount of satisfaction can only be described in hypothetical terms. We may conclude with confidence, however, that the pizza provided him with utility.

The assumption is made in economics that people continually try to maximize their utility, usually within their budget constraints. Generally speaking, if the utility of a good is greater than its cost, people will buy more of that good. Likewise, when the cost exceeds a good's utility, they won't purchase it. Thus, if the utility of a good is greater than its cost, people will buy more of that good. Likewise, when the cost exceeds a good's utility, they will not purchase it.

As stated previously, we have an economic system for only one reason: resources are scarce relative to human wants. The three basic resources we have at our disposal are land, including all natural resources; labor; and capital, including physical resources produced by labor. Economists refer to these resources as "factors of production" because they are used to 


\begin{tabular}{ccc}
\hline TABLE 1 & $\begin{array}{l}\text { Illustration of the Law of } \\
\text { Diminishing Marginal Utility }\end{array}$ \\
\hline $\begin{array}{c}\text { Quantity } \\
\text { Consumed }\end{array}$ & $\begin{array}{c}\text { Total } \\
\text { Utility }\end{array}$ & $\begin{array}{c}\text { Marginal } \\
\text { Utility }\end{array}$ \\
\hline 0 & 0 & - \\
\hline 1 & 3 & 3 \\
\hline 2 & 5 & 1 \\
\hline 3 & 6 & 0 \\
\hline 4 & 6 & 2 \\
\hline
\end{tabular}

\begin{tabular}{cc}
\hline \multicolumn{1}{|c|}{ TABLE 2 } & Demand Schedule for Pizza \\
\hline Price per Pizza & Pizzas Purchased per Week \\
\hline$\$ 6$ & 80 \\
\hline$\$ 8$ & 64 \\
\hline$\$ 10$ & 48 \\
\hline$\$ 12$ & 32 \\
\hline$\$ 14$ & 16 \\
\hline
\end{tabular}

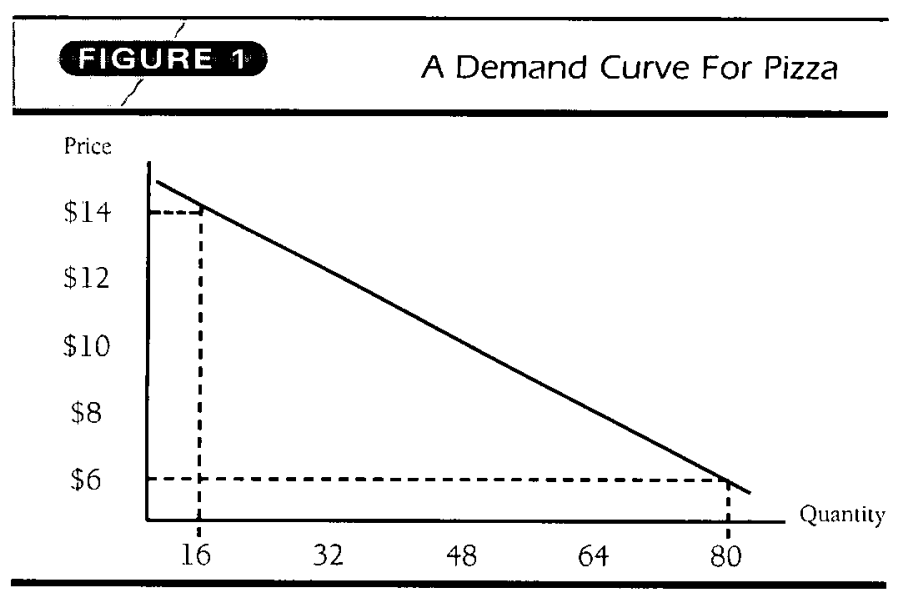

produce things that people desire, called "commodities." Commodities may be divided into "goods" and "services." Pharmacists market both goods and services, although when a transaction does not involve selling a product, they typically do not receive any reimbursement for the service.

"Cost" originates from constraints on our resources. With unlimited resources, every good would be free, like air. However, we live in a state of economic scarcity. Economic resources are allocated according to a "price system." Most goods and services are obtained only by those individuals who are willing and able to pay for them.

If there were no limits on resources, goods would have no value because we would use them until totally satisfied. Also, the marginal utility of any good would be zero since the value of any commodity is determined by its marginal utility. Value, then, originates from our personal desires.

"Marginal" is the economic term for "extra." Thus, the value of a good is measured by its "marginal utility." For example, the marginal utility of purchasing one pair of tennis shoes may be quite high if you currently do not have any tennis shoes, yet the marginal utility of purchasing a second pair of tennis shoes at the same time would be lower. Furthermore, if a person has enough money for only only one pair of shoes, the shoes he buys will cost not only the money he pays for them, but also the satisfaction (utility) he gives up by not being able to spend that money on something else, such as a new pair of pants. Loss of satisfaction from the commodities a person cannot buy is called an "opportunity cost" for getting utility from what he did buy.

\section{Law of Diminishing Marginal Utility}

There is an economic law that states that the utility of any good declines the more one consumes of it. In other words, the more we have of a good, the less we desire it. This is referred to as the "law of diminishing marginal utility." A person who likes pizza will receive some utility if he eats a slice of pizza for lunch. If he eats a second piece, it provides less utility than the first one. A third piece of pizza provides still less. Eventually, the cost of a slice of pizza would exceed its marginal utility and the person would not purchase more (see Table 1).

\section{Law of Demand}

The two most important economic concepts are demand and supply. The theories of supply and demand demonstrate how millions of individual consumer decisions interact to determine market prices for the goods and services available. Buyers exert a market force on prices by the amount of goods and services they demand and suppliers exert a market force based on their ability and willingness to supply products for consumption.

A "demand schedule" shows the various amounts of a commodity consumers are willing and able to purchase at each specific price in a set of possible prices during some specified period of time. Table 2 shows a hypothetical demand schedule for pizza.

According to the table, as the price of pizzas increases, lewer of them are purchased. This illustrates the "law of demand" which states that as price falls, the corresponding quantity demanded rises; alternatively, as price increases, the corresponding quantity demanded falls. In short, there is an inverse relationship between price and quantity demanded.

\section{The Demand Curve}

The law of demand can be illustrated by drawing a demand curve. Figure 1 represents the demand curve for the demand schedule illustrated in Table 2.

Demand curves slope downward and to the right. This graph- 
ic illustration of the data in Table 2 shows the inverse relationship between the price of pizzas and the quantity demanded.

\section{Changes in Demand}

It is important to distinguish between the terms "change in quantity demanded" and "change in demand." A change in quantity demanded refers to movement along a given demand curve. In Figure 1, for example, a decrease in the price of a pizza from $\$ 10$ to $\$ 8$ results in an increase in the quantity demanded, from 48 to 64 pizzas. This increase is referred to as a change in the quantity demanded.

On the other hand, various factors can result in an entire demand curve shifting and this movement is referred to as a "change in demand." Figure 2 shows that demand curve " $\mathrm{D}$ " has moved to the right to demand curve "D,", representing what is meant by a change in demand. Since the demand curve has shifted to the right, the demand has increased. A movement from right to left would mean demand has decreased.

There are five factors that cause consumers to change their demands for a good: prices of related goods; money income of the consumer; number of consumers in the market; attitudes, tastes, and preferences of the consumer; and consumer expectations with respect to future prices and incomes.

Prices of related goods. When the price of one good and the demand for another good are directly related, we say the two products are "substitute goods." An example is the relationship between beef and chicken. As the price of beef increases, the demand for chicken increases, (assuming the chicken was reasonably priced) all else being equal. Increased coffee prices cause the consumer demand for tea to increase. To a degree, many drugs or drug classes may be substitutes for each other (e.g., aspirin, acetaminophen, NSAIDs, and now COX-2 inhibitors).

On the other hand, when the price of one good and the demand for another good are inversely related, the two products are referred to as "complementary goods." In this case, an increase in the price of one good can cause a decrease in the demand for another good. An example would be the relationship between computer printers and printer cartridges. As the price for computer printers decreases, more people will purchase them, thus causing an increase in the demand for printer cartridges. In the prescription market, potassium supplements are often complements of potassium-depleting diuretics.

Commodities whose demand increases with an increase in income are called superior, or "normal goods." Some examples are a sirloin steak, a new sports car, or a summer home on the lake. Since the demand for health care services increases as consumers' incomes rise, health care is a normal good. Poor people may have as much need for health care but their demand is less than that of wealthier individuals. This helps to explain why there are more hospitals and physicians in high-income areas than in the inner city.

Goods whose demand decreases with an increase in income are called "inferior goods." Examples here are used cars or generic liquor. An example of an inferior good related to pharmacy could be an OTC drug, as illustrated by a consumer who

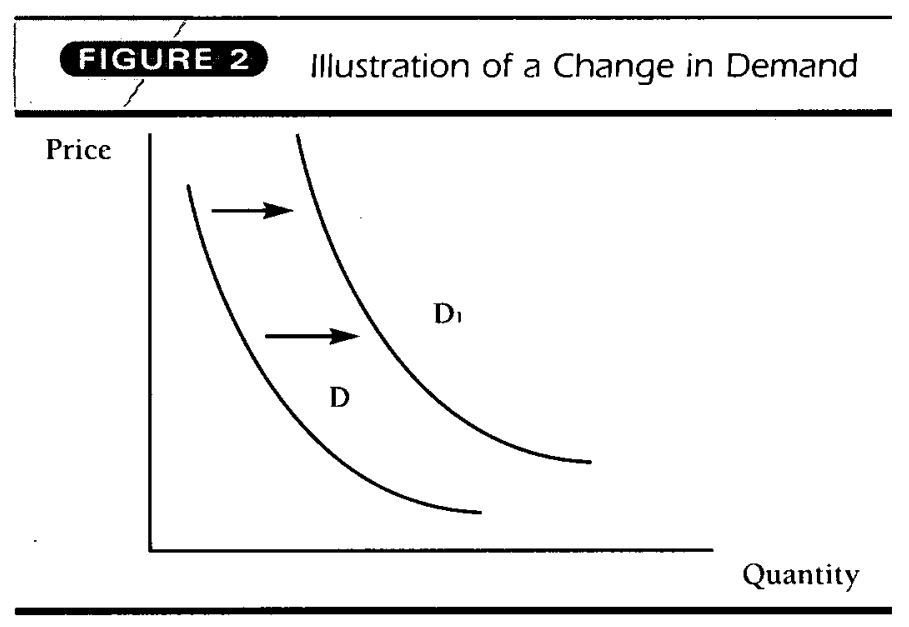

purchases an antacid product because he cannot afford Pepcid AC or to pay for a physician office visit.

Number of consumers in the market. If a manufacturer can increase the number of people who believe they need (or want) to use its product, demand naturally increases (shifts to the right). For example, the U.S. Postal Service discovered they could increase the number of stamp collectors (and increase their revenue) by creating stamps that appealed to children.

Manufacturers' strategies to increase the number of consumers who want a particular type of pharmaceutical is evident. Aspirin products are promoted for minor arthritis, and arthritis products are promoted for headaches and other assorted pains. By finding new indications for prescription drugs, the number of customers (and consequently, demand) for these products will increase. One example is the use of calcium channel blockers (originally used for treatment of angina) for prevention of migraine headaches. Another example is minoxidil, which was originally marketed as Loniten for treatment of hypertension, but reformulated as Rogaine for hair growth.

Attitudes, tastes, and preferences of consumers. Consumer attitudes, tastes and preferences are affected greatly by advertising or by fashion changes. The manufacturer of NyQuil liquid cold medicine, for example, created a demand for its product by distinguishing it as a medication that works while a person is sleeping. This appeal, combined with the distinguishing characteristic that the medication is a liquid rather than a tablet or capsule, resulted in an increased demand for the product and its sales skyrocketed. On the other hand, the environmental concerns associated with polystyrene containers for fast food has decreased demand for these products.

Consumer expectations. A good example of how consumer expectations of future prices and personal incomes affect demand was recently seen in the demand for oranges. Newspapers published articles reporting that Florida's orange crop had been badly damaged by freezing weather and this shortage of oranges would cause orange juice prices to rise in the United States. Consumers responded by immediately buying several cans of frozen orange juice concentrate to have on hand. Of course, the grocers understand economics and read 


\section{Exercise 1-Change in Demand}

A rightward shift in the demand curve for a commodity means that

a. consumers' incomes may have fallen.

b. supply conditions are more favorable.

c. consumers are willing to buy more of the good at each price than previously.

d. the price of the commodity has decreased.

\section{Answer}

Answers "a" is not correct because a drop in buyers' incomes would decrease their ability and willingness to pay and, therefore, decrease their demand, which would be represented by a leftward shift of the demand curve.

Answer " $b$ " is incorrect because a change in supply does not cause a change in demand-supply and demand are affected by a different set of factors.

Answer " $c$ " is correct because a rightward shift in the demand curve represents an increase in demand. Because of this increase in demand, consumers are willing to buy more at each given price.

Answer " $d$ " is incorrect because a change in price causes a change in the quantity demanded; not a change in demand. In other words, a given demand curve represents the various quantities that would be demanded by consumers for each of the prices that may be charged by the seller. A change in price simply moves you up and down the curve; it doesn't change (shift) the curve itself.

\section{Exercise 2-Change in Demand}

If the price of Product $A$ decreases, what is the effect on Product B (a substitute)?

a. The quantity demanded increases.

b. The quantity demanded decreases.

c. The demand increases.

d. The demand decreases.

\section{Answer}

Answers "a" and "b" are incorrect because a change in price of a product causes a change in the demand of a substitute product; not a change in quantity demanded. In other words, the demand curve itself is changed; you don't just move up and down the curve.

Answer " $\mathrm{c}$ " is incorrect because a decrease in the price of Product $A$ means that more consumers will switch from $B$ to $A$, thereby decreasing the amount of $B$ that people buy at a given price.

Answer " $d$ " is correct for the same reason. the same newspaper articles, so they immediately raised the price of orange juice.

Another example of how consumer expectations could affect demand is illustrated by the $\mathrm{Y} 2 \mathrm{~K}$ scare in which it was feared that patients would create a drug shortage by increasing their demand for pharmaceuticals in anticipation of imagined supply problems at the beginning of the new year.

Despite the tremendous increases in the cost of building a home, the number of houses being built has been increasing recently. There are at least two reasons for this: (1) economists are predicting that housing costs will continue to rise, so people are deciding to build now before costs go any higher; and (2) people are anticipating a continual growth in their incomes, so they are building homes based on what they expect to be earning in a few years.

In summary, an increase in the demand for Product X can be caused by any of the following:

- increase in the price of Product $Y$ if it is a substitute for

Product $X$; a decrease in the price of Product $Y$ if it is a complement to Product $X$;

- rise in one's income if Product X is a normal good or a decrease in one's income if Product $\mathrm{X}$ is an inferior good;

- increase in the number of buyers for Product $\mathrm{X}$ in the market;

- favorable change in the consumer tastes for Product X; and

- consumer expectation that the price of Product X will increase in the future.

\section{Law of Supply}

Supply, like demand, is a schedule. A "supply schedule" shows the number of goods or services offered for sale at specific prices during some specified period of time. Table 3 shows a hypothetical supply for a producer of pizzas.

As shown in the table, as the price increases, more pizzas are produced. This illustrates the "law of supply" which states that as the price that people are willing to pay rises, the corresponding quantity supplied also increases. In short, there is a direct relationship between price and quantity supplied.

\section{The Supply Curve}

Just as we illustrated the law of demand by drawing a demand curve, the law of supply can be illustrated with a supply curve. Figure 3 illustrates the supply curve for the supply schedule given in Table 3. Supply curves slope upward to the right, illustrating a direct relationship between the price that people are willing to pay for pizzas and the quantity supplied to consumers.

\section{Changes in Supply}

The terms "change in quantity supplied" and "change in supply" are used similarly to those discussed under demand. The following factors bring about a change in supply: production technology; number of sellers in the market; resource costs (materials and wages); prices for related goods; and seller expectations. 
costs of production decrease. At a given price, suppliers make more profits and, consequently, are willing to produce more. Technological advances include equipment (e.g., more efficient tractors), supplies (e.g., genetically engineered seeds), methods of production (e.g., crop rotation), or management techniques (e.g., using the advice of agricultural experts).

The number of sellers in the market. More producers create more output. Therefore, as the number of sellers in a market increases, supply also increases and is represented by a rightward shift in the supply curve.

Resource costs. As the costs of resources (materials, labor, rents, interest rates, etc.) increase, sellers are not able to make as much profit at a given price. Companies have less incentive to produce when input costs increase. On the other hand, a decrease in resource costs will cause supply to increase. Lower fertilizer prices, for example, can cause an increase in agricultural production that will encourage farmers to produce more. Some employers have used this same principle to predict that increases in the minimum wage will hurt production levels.

Prices for related goods. Producers have two types of related goods: "substitute products" and "joint products." Substitute products are those that are produced with the same, or similar, inputs. If the price of one product increases, it will affect the supply of another product. For example, if the price of wheat increases, farmers will start growing less com and more wheat. Therefore, the price of wheat affects the supply of corn.

Goods almost always produced together are known as "joint products." Leather and beef are joint products because they cannot be produced separately. An increase in the price of beef will induce a greater quantity of beef supplied and, consequently, the supply of leather will increase even if the price of leather falls.

Seller expectations. If sellers expect prices to increase in the near future, they may increase production now or withhold some product from the market. This happens in agriculture when farmers try to time sales to obtain favorable prices. The impact of sellers' expectations is also illustrated by the $\mathrm{Y} 2 \mathrm{~K}$ scare in which some pharmaceutical manufacturers, wholesalers, and retailers increased their supplies in anticipation of a potential shortage. Even the government printed more money to accommodate the possible hoarding of cash.

\section{Equilibrium Price}

The price system-the interaction of supply and demanddetermines how economic resources are allocated. Because buyers in any market always want to demand more units of a good at a lower price and sellers always want to supply more units of that good at a higher price, a "market equilibrium price" can be achieved that brings about economic efficiency by exactly balancing these competing market forces. This market equilibrium price represents the point where the supply and demand curves intersect, as illustrated in Figure 4.

Market equilibrium occurs when pizza is priced at $\$ 10.00$ because at that price, the quantity demanded equals the quantity supplied. At the equilibrium price of $\$ 10.00$, both seller and buyer are satisfied with the price. At any price other than

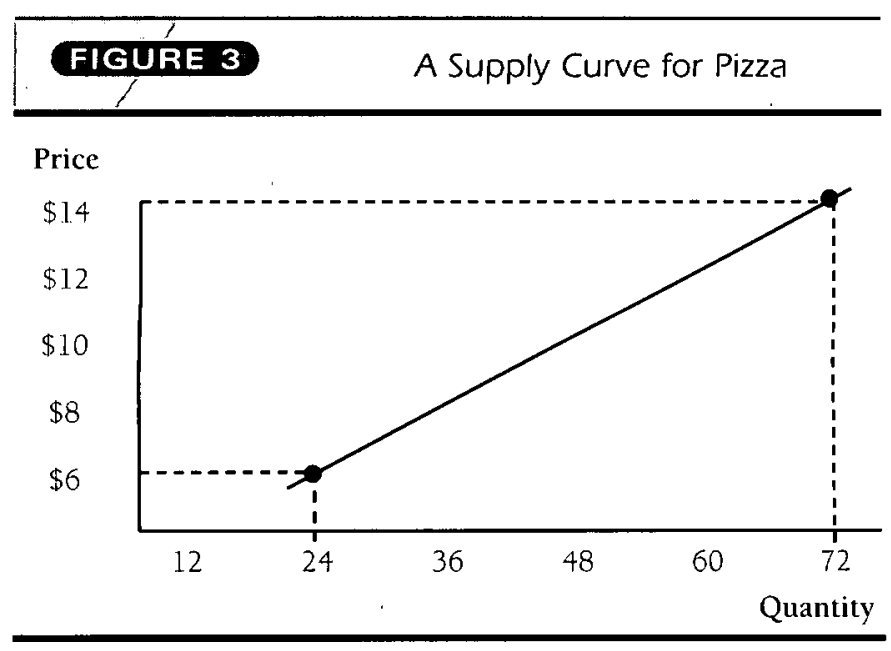

TABLE 3

Supply Schedule for Pizza

Price per Pizza

Pizzas Purchased per Week

\begin{tabular}{cc}
\hline$\$ 6$ & 24 \\
\hline$\$ 8$ & 36 \\
\hline$\$ 10$ & 48 \\
\hline$\$ 12$ & 60 \\
\hline$\$ 14$ & 72 \\
\hline
\end{tabular}

FIGURE 4 Supply and Demand Curve for Pizza

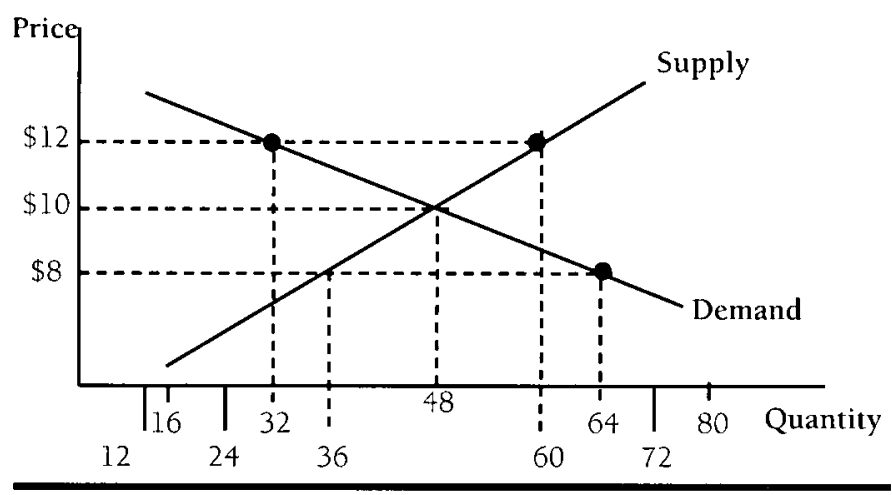

$\$ 10.00$, economic forces will attempt to change the price. These economic forces can be illustrated with two cases.

Case 1: Price increases to $\$ 12.00$. At a price of $\$ 12.00$, pizza sellers produce 60 pizzas while consumers only want to buy 32 . Thus, there is a surplus (excess supply) of pizzas. What happens? Consumers only buy 32 . Eventually, one pizza seller will lower his price to get rid of his unsold pizzas, which will increase the quantity demanded for his product. Other sellers also lower their price until at $\$ 10.00$, the demands of the consu- 


\begin{tabular}{|ccc}
\hline TABLE 4 & \multicolumn{2}{c}{$\begin{array}{c}\text { Demand Schedule for an } \\
\text { Elastic Good }\end{array}$} \\
\hline Price & $\begin{array}{c}\text { Expected Number } \\
\text { to be Sold }\end{array}$ & $\begin{array}{c}\text { Total } \\
\text { Revenue }\end{array}$ \\
\hline$\$ 2$ & 56 & $\$ 112$ \\
\hline$\$ 3$ & 36 & $\$ 108$ \\
\hline$\$ 4$ & 26 & $\$ 104$ \\
\hline$\$ 5$ & 20 & $\$ 100$ \\
\hline
\end{tabular}

\begin{tabular}{ccc}
\hline TABLE 5 & \multicolumn{2}{c}{$\begin{array}{c}\text { Demand Schedule for an } \\
\text { Inelastic Good }\end{array}$} \\
\hline Price & $\begin{array}{c}\text { Expected Number } \\
\text { to be Sold }\end{array}$ & $\begin{array}{c}\text { Total } \\
\text { Revenue }\end{array}$ \\
\hline$\$ 2$ & 45 & $\$ 90$ \\
\hline$\$ 3$ & 31 & $\$ 92$ \\
\hline$\$ 4$ & 24 & $\$ 96$ \\
\hline$\$ 5$ & 20 & $\$ 100$ \\
\hline
\end{tabular}

\begin{tabular}{ccc}
\hline TABLE 6 & \multicolumn{2}{c}{$\begin{array}{c}\text { Demand Schedule for a } \\
\text { Unitary Good }\end{array}$} \\
\hline Price & $\begin{array}{c}\text { Expected Number } \\
\text { to be Sold }\end{array}$ & $\begin{array}{c}\text { Total } \\
\text { Revenue }\end{array}$ \\
\hline$\$ 2$ & 50 & $\$ 100$ \\
\hline$\$ 2.50$ & 40 & $\$ 100$ \\
\hline$\$ 4$ & 25 & $\$ 100$ \\
\hline$\$ 5$ & 20 & $\$ 100$ \\
\hline
\end{tabular}

also lower their price until at $\$ 10.00$, the demands of the consumers equal what the sellers are willing to produce at that price.

Case 2: Price decreases to $\$ 8.00$. At a price of $\$ 8.00$, pizza sellers produce 36 pizzas while consumers want to buy 64 . Thus, there is a shortage (excess clemand) for pizzas. What happens? Consumers order a pizza, but the seller is sold out. The seller notices that each day, he sells every pizza he has produced. Consumers might even be calling him to say they will pay him extra if he will save a pizza for them. This increased demand and opportunity to increase the price serve as incentives for the seller to produce more pizzas. When the price gets to $\$ 10.00$, both the seller and buyer are satisfied. Everyone who wants to buy a pizza does so, and the seller does not have any pizzas left at the end of the day.

\section{Elasticity of Demand}

Elasticity is a widely used economic concept that measures the responsiveness of consumer demands to a change in price. As stated previously, the demand curve slopes downward because as the price of a commodity decreases, the quantity demanded increases. However, the degree (or angle) of this downward slope varies with different types of goods. Depending upon the slope, a commodity is said to have an elastic demand, inelastic demand, or unitary demand.

The producer (or seller) of any good typically can charge whatever price he desires. Naturally he will sell his good at the price which results in maximizing his profits. If the producer can lower his selling price and make more money, he will do so. Likewise, if he can raise his selling price and make more money, he will do so. The key term in such an analysis is not the good's selling price, but rather the "total revenue" the producer receives. Selling price multiplied by quantity sold equals total revenue. Whether a change in the selling price will result in an increase or decrease in total revenue depends upon the "elasticity of demand" for the particular good.

\section{Elastic Demand}

Suppose a producer is faced with a demand schedule for one of its goods (see Table 4). As the price of the good increases, the producer's total revenue decreases. This is a good with an elastic demand. With elastic demand, an increase in price causes the quantity demanded to decrease enough to result in a decrease in total revenue. Conversely, a decrease in price causes the quantity to increase enough to result in an increase in total revenue. Thus, when a good has an elastic demand, the quantity demanded is very sensitive to the price. An example of a good with an elastic demand is a brand of gasoline. When a Shell Oil gas station proprietor lowers his price below his competitors, his sales likely will increase so much that his total revenue will increase. The opposite will occur when he raises his price above other brands. That is why gasoline prices are so standardized within a community; the demand for any brand of gasoline is extremely sensitive to price. Note that gasoline is very narrowly and specifically defined as a particular brand of gasoline at a particular station, and it is understood that this station's gasoline has interchangeable substitutes at many competing stations. As we'll see when we look at prices for gasoline in general rather than prices at particular stations, demand is more inelastic.

\section{Inelastic Demand}

Suppose a producer is faced with a demand schedule for one of its goods (see Table 5). As the price of the good increases, total revenue increases. This is a good with an inelastic demand. With inelastic demand, an increase in price causes only a slight decrease in the quantity demanded resulting in an increase in total revenue. Conversely, a decrease in price causes the quan- 
tity demanded to increase, but the increase is so small that the result is a decrease in total revenue. Thus, when a good has an inelastic demand, the quantity demanded is relatively insensitive to price. An example of a good with an inelastic demand is gasoline (when defined as noted above). An automobile will not operate without gasoline, so when the price of gasoline increases at all gas stations, people will buy a little less, but they will still buy enough to give the gas station proprietor an increase in total revenue. Thus, gasoline has a relatively inelastic demand. While the quantity of gasoline demanded by consumers doesn't tend to depend much on price (thus, inelastic demand), the quantity purchased at a particular station does depend on how prices at that station compare to competitors' (thus, elastic demand). Studies show that demand for health care services, including prescription drugs, is quite inelastic. People with true emergencies (such as a broken arm or a heart attack) will seek treatment without regard to the cost.

A logical question to ask at this point is "If total revenue increases every time the price of an inelastic good increases, what keeps the price from rising to infinity?" Usually competition keeps prices in check or, in the case where there isn't much competition (such as public utilities), government intervention may be needed to regulate prices. While MCOs in the U.S. have controlled costs by facilitating competition among some pharmaceutical products through generic and therapeutic substitution, government agencies in Canada and Europe control costs by regulating pharmaceutical manufacturers' prices.

Unitary Demand. Suppose a producer is faced with a demand schedule for one of its goods (see Table 6). As the price of the good increases or decreases, the producer's total revenue remains the same. This characterizes a good with a "unitary demand." Unitary demand is not common in the actual marketplace; products tend to have either an elastic or inelastic demand.

\section{Determinants of Elasticity of Demand}

What makes the demand for a particular good or service elastic or inelastic? In answering this question, it must first be understood that our discussion of elasticity of demand will relate only to short-run demand. To differentiate between short-run and long-run, consider that a consumer has two resources when shopping: money and time. In other words, a person can purchase a demanded good today with money or he can wait until a later time when he may have more money, the price of the demanded commodity may decrease, or his demand may change to favor another commodity. Elasticity of demand for a given commodity changes when one talks about the short run versus the long run because a longer time span allows people to pursue more alternatives (i.e., substitutes).

For example, with the price of gasoline increasing, automobile owners continue to buy it because they need their cars. However, in the long run, alternative means of transportation, such as buses, commuter trains, or car pools may be sought. The desired result, of course, is to eventually decrease one's need for, and thus one's demand for gasoline in the face of higher gasoline prices.

\section{Exercise 3-Change in Equilibrium Due to an Increase in Supply}

When supply increases in a competitive market

a. equilibrium price will fall.

b. demand will fall.

c. shortages will emerge.

d. quantities sold will decrease.

\section{Answer}

Answer " $a$ " is correct because the new supply curve will shift to the right and intersect with the demand curve at a new point which represents both a decrease in equilibrium price and an increase in equilibrium quantity (see Figure 5).

Answer " $b$ " is incorrect because a change in supply does not cause a change in demand-supply and demand are affected by different, independent factors.

Answer " $c$ " is incorrect because an increase in supply will result in a temporary surplus that will be corrected when prices drop to a new equilibrium point. At this new equilibrium point the quantity demanded will equal the quantity supplied.

Answer "d" is incorrect for the same reason given for answer "a."

\section{Exercise 4-Elasticity of Demand}

If demand is price-elastic, an increase in supply (i.e., a rightward shift of the supply curve) will cause a relatively

a. large decrease in quantity demanded.

b. large increase in quantity demanded.

c. small decrease in quantity demanded.

d. small increase in quantity demanded.

\section{Answer}

Answers "a" and "c" are not correct because an increase in supply will result in an increase in the quantity demanded.

Answer " $b$ " is correct because an elastic demand curve, by definition, means that consumers are very sensitive to changes in price and any change in price will result in a disproportionately greater change in quantity demanded. Therefore, an increase in supply of a product with an elastic demand curve will result in a large increase in quantity demanded (see Figure 5). "c".

Answer " $d$ " is incorrect for the reason explained for answer

\begin{tabular}{|c|c|}
\hline FIGURE 5 & $\begin{array}{l}\text { Change in Equilibrium for a } \\
\text { Product With an Elastic Demand }\end{array}$ \\
\hline
\end{tabular}

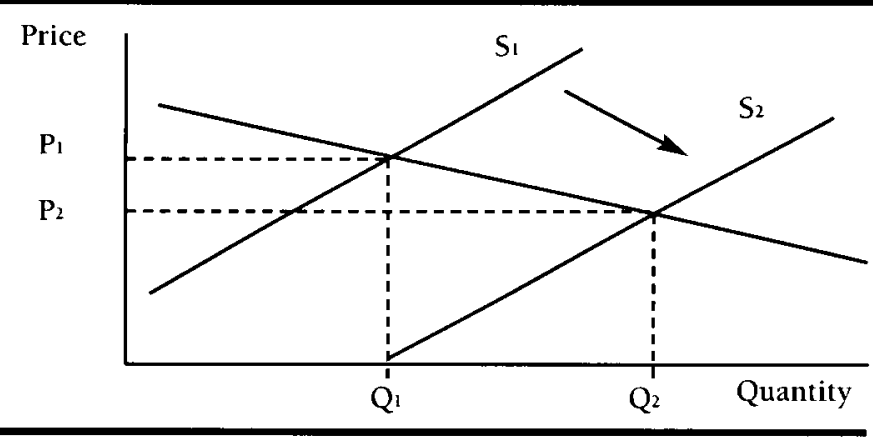




\section{Exercise 5-Elasticity of Demand}

Elasticity of demand will increase as the

a. number of available substitutes decreases.

b. price of the good relative to income decreases.

.. c. time horizon increases.

\section{Answer}

Answer "a" is incorrect because the greater the number of -substitute-goods available for a particular commodity, the more elastic the demand for that commodity will'be.

Answer " $b$ " is incorrect because those commodities that account for a large portion of a person's income will be more elastic than for purchases that are relatively inexpensive.

Answer " $c$ " is correct because the longer time frame allows consumers to consider more alternatives and find more substitutes for a product in the long run.

There are three principal determinants of elasticity: the availability of substitutes for the commodity; the price of a commodity relative to consumers' incomes; and the number of alternative uses for the commodity.

Availability of substitutes. When the price of one good and the demand for another good are directly related, the two products are substitute goods. The example previously given was the relationship between beef and chicken. The greater the number of substitute goods available for a particular commodity, the more elastic the demand for that commodity.

The more narrowly and specifically a commodity can be described, the more substitutes it will have and thus the demand for it will be more elastic. For example, when a person is suffering from athlete's foot, he probably has a strong desire for an antifungal. Because there are no other OTC drugs that will relieve athlete's foot, the demand for antifungals is inelastic. However, there are numerous antifungal products available so the demand for any particular brand of antifungal is elastic.

Sellers have found that some customers have more substitutes than others. Business travelers are not as flexible as individuals traveling on vacation. Vacation travelers have a more elastic demand for air travel and are able to obtain less expensive air fares. Segregating customers and charging prices according to customers' elasticity of demand is known as "differential pricing" (also known as price discrimination). For price discrimination to work, it must be difficult for buyers to resell to one another. Price differences reflecting actual cost of production differences, such as volume discounts, do not represent price discrimination.

Price relative to consumers' incomes. The demand for commodities that account for a large portion of a person's income will be more elastic than for purchases that are relatively inexpensive. For example, most managers are more price-conscious when they shop for a computer than paper clips. Since envelopes and paper clips account for a negligible fraction of a company's budget, changes in price likely will have little effect on the quantity demanded. Thus, we say the demand for these products is relatively inelastic.

Number of alternative uses. The fewer uses a commodity has, the more likely its demand to be inelastic. People tend to be selective in a commodity's use as its price increases. An example of this occurred several years ago when the price of sugar rose greatly. When the price of sugar increased, people found they still needed it for some types of foods, but they did not need nearly as much as they had been using. They reduced the number of ways sugar could be used, thus changing its demand from elastic to inelastic.

\section{Elasticity of Demand for Prescription Drugs}

The three determinants of elasticity can be applied to prescription drugs. First, when a physician writes a prescription order for a specific drug for an ambulatory patient, there usually are no substitute goods involved. The patient has the choice of having the prescription filled or not. If he has the prescription filled, he often has no choice as to what drug will be dispensed. (Product selection legislation gives the patient some choices in certain cases, but the above description is accurate for drugs protected by patents. This, of course, is altered to some degree by the adoption of formularies and therapeutic selection.)

Second, prescription drugs take up a relatively small portion of most people's income. Third, prescription drugs have few alternate uses. An antibiotic is prescribed for a specific type of infection but it has no value in treating most other types of physical or mental ailments.

In summary, prescription drugs have few, if any substitutes, they represent a relatively small portion of one's income (particularly if one pays only a copayment), and they have few uses other than that purpose for which they are prescribed. Thus, a prescription drug has an inelastic demand. This means its demand is relatively insensitive to changes in price.

There are two additional factors in the pharmaceutical industry that contribute to the inelasticity of demand for prescription drugs. First, a physician's role as the decision-maker in the choice of drugs tends to make price a secondary consideration. Second, the industry promotes product differentiation between drugs, reducing the importance of price to the physician in selecting a particular drug to prescribe. In other words, the industry is successful at reducing the perceived number of available substitutes. Also, having a third-party plan pay all or part of a person's prescription drugs significantly increases the inelasticity of demand for those drugs.

\section{Conclusions}

This Continuing Education article presents basic economic concepts such as supply, demand, equilibrium price, the price system, price discrimination, and elasticity of demand. The next article will discuss how economic forces in the health care marketplace compare to those of other industries and how health care can be influenced by competition.

Managed care pharmacists must understand and use economic principles to effectively design and administer prescription benefit programs. By understanding these basic principles one can begin to appreciate the factors affecting economics in the health care industry. 
Upon completion of this article, the successful participant should be able to:

1. Define basic economic concepts of utility, demand, supply, equilibrium price, the price system, price discrimination, and elasticity of demand.

2. Explain the factors that cause a change in the demand or supply of a product or service.

3. Determine the impact that a change in demand or supply will have on the equilibrium price of a product or service.

4. Explain how elasticity of demand influences the effect that a change in price will have on the total revenue earned by a firm.

5. Give examples of how basic economic principles apply to contemporary health care issues.

\section{SELF-ASSESSMENT QUESTIONS}

1. A change in demand means that there has been a

a. movement along a given demand curve.

$b$. shift to the right or left of a given demand curve.

c. shift to the right or left of a given supply curve.

d. permanent disequilibrium condition created in the market.

2. In general, supply curves slope upward to the right because

a. increases in the price of a commodity lead to rightward shifts of the supply curve.

b. rising prices motivate producers to offer more units for sale.

c. technology progresses over time, increasing the ability of firms to produce more at existing prices.

d. of increases in input prices as production is increased.
3. In free markets, the price system encourages producers to meet consumers' wants because

a. it signals producers as to which goods are most likely to be in demand.

b. producers have the public interest in mind.

c. it allows government to direct firms to the best technique.

d. consumers are generally willing to pay more than the actual price.

4. The law of diminishing marginal utility means that as more of a commodity is consumed, total utility will

a. rise but at a declining rate.

b. fall steadily, eventually becoming negative.

c. remain unchanged until the individual is satiated.

d. rise but at an increasing rate.

5. An increase in consumers' wages will cause:

a. an increase in both equilibrium quantity and equilibrium price for a given commodity.

b. a decrease in both equilibrium quantity and equilibrium price for a given commodity.

c. an increase in equilibrium quantity and a decrease in equilibrium price for a given commodity.

d. a decrease in equilibrium quantity and an increase in equilibrium price for a given commodity.

6. A large number of sellers dropping out of the market will cause

a. an increase in both equilibrium quantity and equilibrium price for a given commodity.

b. a decrease in both equilibrium quantity and equilibrium price for a given commodity.

c. an increase in equilibrium quantity and a decrease in equilibrium price for a given commodity.

d. a decrease in equilibrium quantity and an increase in equilibrium price for a given commodity.

7. Economics is the study of

a. how individuals and society decide to use scarce resources to produce goods and services and distribute them for consumption.

$b$. how to manage successfully a profitable business.

c. how to make money in the stock market.

d. the ways government can achieve an equitable distribution of income.

8. Along a demand curve, which of the following is allowed to change?

a. consumer income.

b. consumer tastes and preferences.

c. the good's own price.

d. prices of substitutes and complements.

9. Which of the following illustrates a move along a demand curve?

a. John buys more apples because the price of oranges has decreased.

b. Ruth rents fewer videos because her income has decreased.

c. Diane buys fewer lobsters because the price of lobsters has increased

d. David buys more books because his preference for reading has increased.

10. If the supply of a product increases,

a. more product will be sold and prices will be higher.

$b$. more product will be sold and prices will be lower.

c. less product will be sold and prices will be higher.

$d$. less product will be sold and prices will be lower. 
DEMOGRAPHIC INFORMATION (Not for scoring.)

11. In what type of setting do you work? (Leave blank if none of the responses below applies.)
a. $\mathrm{HMO}$
b. $\mathrm{PPO}$
c. Indemnity insurance
d. Pharmacy benefits management
e. Other

12. Did this program achieve its educational objectives?
a. Yes
b. No

13. How many minutes did it take you to complete this program, including the quiz? (Fill in on answer sheet.)
14. Did this program provide insights relevant or practical for you or your work?
a. Yes
b. No

15. Please rate the quality of this $C E$ article.
a. Excellent
c. Fair
b. Good
d. Poor

\section{INSTRUCTIONS}

AG This test affords 1.5 hours (.15 CEUs) of continuing pharmaceutical education in all states that recognize the American Council on Pharmaceutical Education. To receive credit, you must score at least $70 \%$ of your test answers correctly. To record an answer, darken the appropriate block below. Mail your completed answer sheet to: Academy of Managed Care Pharmacy, 100 N. Pitt Street, Suite 400, Alexandria, VA 22314. Assuming a score of $70 \%$ or more, a certificate of achievement will be mailed to you within six to eight weeks. If you fail to achieve $70 \%$ on your first try, you will be allowed only one retake. The ACPE Provider Number for this lesson is 233-000-00-001-H04. This offer of continuing education credits expires February 28, 2001.
A $\quad$ B $\quad$ C $\quad$ D
A $\quad$ B $\quad$ C $\quad$ D
11. $\square \mathrm{A} \quad \square \mathrm{B} \quad \square \mathrm{C} \quad \square \mathrm{D} \quad \square \mathrm{E}$
1. $\square \square \square \square$
2. $\square \quad \square \quad \square \quad \square$
3. $\square \quad \square \quad \square \quad \square$
4. $\square \quad \square \quad \square \quad \square$
5. $\square \square \square \square$
6. $\square \square \square \quad \square$
7. $\square$ ๑ $\square \square$
8. $\square \quad \square \quad \square \quad \square$
9. $\square \quad \square \quad \square \quad \square$
10. $\square \quad \square \quad \square \quad \square$
12. $\square$ Yes $\square$ No
13. Minuies
14. $\square$ Yes $\square$ No
15. $\square \mathrm{A} \quad \square \mathrm{B} \quad \square \mathrm{C} \quad \square \mathrm{D}$

Participant Identification: Please type or print.

Social Security \#: For Identification Purposes Only
Date:

Work Phone \#:

Name:

LAST FIRST

Company:

Address:

STREET (with Apt. No.) or P.O. Box

CITY

STATE

ZIP

State \& Lic. No: STATE LICENSE NO.
Member Type:
$\square$ Active
Supporting Associate
$\square$ Student
$\square$ Nonmember

Signature: 